\title{
Para além do ingresso: as cotas nos Institutos Federais e os desafios de uma formação técnica e profissional emancipadora
}

\author{
Beyond admission: racial quotas in Federal Institutes and the challenges of emancipatory technical \\ and professional training \\ Además de la admisión: las cuotas raciales en los Institutos Federales y los desafíos de una \\ formación técnica y profesional emancipadora
}

Recebido: 06/07/2021 | Revisado: 11/07/2021 | Aceito: 09/08/2021 | Publicado: 12/08/2021

Lucilene Machado dos Santos
ORCID: https://orcid.org/0000-0001-5935-4012
Instituto Federal de Educação, Ciência e Tecnologia do Norte de Minas Gerais, Brasil
E-mail: santoslu668@gmail.com
Suzana Alves Escobar
ORCID: https://orcid.org/0000-0002-7975-4627
Instituto Federal de Educação, Ciência e Tecnologia do Norte de Minas Gerais, Brasil
E-mail: suzana.escobar@ifnmg.edu.br

\section{Resumo}

Este artigo propõe uma reflexão sobre os desafios que pretos e pardos enfrentam para acessar o sistema educacional brasileiro e a importância da Lei Federal 12.711/12 na implementação de cotas, em especial, as raciais, na rede federal de ensino. Rememorar os aspectos históricos relacionados ao processo de escravização de negros e de suas implicações para a formação da classe trabalhadora brasileira constituem pressupostos indispensáveis para compreensão da política de cotas regulamentada através da Lei Federal 12.711/12. A Lei de Cotas tem sido um importante mecanismo para ampliação do acesso à educação, contudo, esse ingresso no sistema educacional não pode estar apartado da ideia de emancipação, que se constitui como um dos pilares para construção de uma sociedade mais justa e igualitária. Nesse sentido, propõe-se a compreensão do ensino técnico ofertado pelos Institutos Federais sob uma perspectiva emancipatória, comprometida com a transformação da sociedade através da emancipação dos sujeitos.

Palavras-chave: Cotas raciais; Ensino técnico; Formação emancipadora.

\begin{abstract}
This article proposes a reflection on the challenges that blacks and browns face to access the Brazilian educational system and the importance of Federal Law 12.711/12 in the implementation of quotas, especially racial ones, in the federal education network. Recalling the historical aspects related to the process of enslavement of blacks and their implications for the formation of the Brazilian working class constitutes indispensable assumptions for understanding the quota policy regulated through Federal Law 12.711/12. The Quota Law has been an important mechanism for expanding access to education, however, this admission into the educational system cannot be separated from the idea of emancipation, which constitutes as one of the pillars for building a more just and egalitarian society. In this sense, it is proposed to understand the technical education offered by the Federal Institutes under an emancipatory perspective, committed to the transformation of society through the emancipation of the subjects.
\end{abstract}

Keywords: Racial quotas; Technical education; Emancipatory formation.

\section{Resumen}

Este artículo propone una reflexión sobre los desafíos a los que se enfrentan los negros y los marrones en el acceso al sistema educativo brasileño y la importancia de la Ley Federal 12,711/12 en la implementación de cuotas, especialmente raciales, en la red federal de educación. Volver a examinar los aspectos históricos relacionados con el proceso de esclavitud de los negros y sus implicaciones para la formación de la clase trabajadora brasileña constituyen presuposiciones indispensables para entender la política de cuotas regulada por la ley federal 12.711/12. La Ley de Cuotas ha sido un mecanismo importante para ampliar el acceso a la educación, sin embargo, esta entrada en el sistema educativo no puede formar parte de la idea de emancipación, que constituye uno de los pilares para la construcción de una sociedad más justa e igualitaria. En este sentido, se propone la comprensión de la educación técnica que ofrecen los Institutos Federales desde una perspectiva emancipadora, comprometida con la transformación de la sociedad a través de la emancipación de sus ciudadanos.

Palabras clave: Cuotas raciales; Educación técnica; Formación emancipadora. 


\section{Introdução}

A sociedade brasileira tem contribuído, principalmente com o acirramento dos debates das últimas décadas, com as discussões sobre a responsabilidade do Estado na implementação de políticas públicas afirmativas para correção de desigualdades de grupos historicamente marginalizados. Um dos resultados dessas discussões foi a aprovação, após longos anos de discussão, da Lei Federal 12.711/2012 chamada Lei de Cotas.

A referida lei trata da reserva de vagas nas instituições federais para egressos de escolas públicas. Além disso, as vagas reservadas podem também ser associadas a critérios étnicos- raciais. Isso porque, a discussão sobre as desigualdades no acesso à educação ainda persistente na sociedade brasileira configura-se como limitador de oportunidades para os jovens, especialmente negros. Diante disso, optou-se no presente artigo por fazer uma análise com recorte racial, especificamente, das vagas reservadas para autodeclarados pretos e pardos.

Nesse contexto, o Instituto Nacional de Geografia e Estatística (IBGE) no ano de 2019, através da coleta de dados realizada na Pesquisa Nacional por Amostra de Domicílios Contínua (PNAD Contínua), corroboram essa grande desigualdade estrutural no acesso à educação da população preta ou parda em relação à população branca.

No boletim informativo da PNAD Contínua consta que a taxa de analfabetismo das pessoas de 15 anos ou mais de cor preta ou parda é mais que o dobro das pessoas brancas, sendo $8,9 \%$, enquanto que entre as de cor branca é de 3,60\%, conforme se depreende do apontamento abaixo.

$\mathrm{Na}$ análise por cor ou raça, chama-se atenção para a magnitude da diferença entre pessoas brancas e pretas ou pardas. Em 2019, 3,6\% das pessoas de 15 anos ou mais de cor branca eram analfabetas, percentual que se eleva para 8,9\% entre pessoas de cor preta ou parda (diferença de 5,3 p.p.). No grupo etário de 60 anos ou mais, a taxa de analfabetismo das pessoas de cor branca alcançou 9,5\% e, entre as pessoas pretas ou pardas, chegou a $27,1 \%$. Comparando-se os dados de 2019 com 2016, nota-se uma queda de 2,1 p.p. para pessoas de cor branca e de 3,6 p.p. para pretas e pardas. (PNAD contínua, 2020).

Infere-se dos dados acima apresentados que a grande maioria da população analfabeta do país é composta por pessoas da cor preta ou parda, ou seja, pessoas que não tiveram nenhum acesso à educação, denotando a diferença abissal na concretização do direito à educação, aqui constatado apenas sob a perspectiva de ingresso.

Entende-se que as questões e os desafios que envolvem a discussão sobre o acesso à educação para pretos e pardos, bem com os instrumentos da política pública nacional que buscam viabilizar o acesso à educação pública de qualidade, como a instituída pela Lei de Cotas, deve ser permeada pela compreensão do processo de trabalho forçado e escravização de negros vigentes na sociedade brasileira por quase três séculos, porque "próximo ou distante, o passado tem sempre um sentido para nós, sentido que é dado pelo registro da história que nos é contada”. (Ciavatta, 2018, p. 82).

Nesse sentido, objetiva-se analisar a efetividade da Lei 12.711/12 especialmente das cotas para pretos e pardos no âmbito da rede federal de ensino técnico, na perspectiva de compreender como a proposta de uma educação emancipadora dos Institutos Federais a partir do ensino do trabalho como princípio educativo ${ }^{1}$ é importante para formação e educação do jovem que ingressa pelo sistema de cotas, contribuindo para formação de uma sociedade mais igualitária e democrática, que objetivamente garanta o acesso universal à educação, conforme assegurado pelo art. 205, da Constituição Federal de 1988.

\footnotetext{
${ }^{1}$ Diversos autores no Brasil têm tratado do trabalho como princípio educativo (a exemplo de Frigotto (1985); Ciavatta (1990); Saviani (1994)). O princípio educativo do trabalho, segundo Frigotto (2006, p. 247), "é um processo que permeia todo o ser do homem e constitui a sua especificidade. (...) Na sua dimensão mais crucial, ele aparece como atividade que responde à produção dos elementos necessários e imperativos à vida biológica dos seres humanos como seres ou animais evoluídos da natureza. Concomitantemente, porém, responde às necessidades de sua vida cultural, social, estética, simbólica, lúdica e afetiva. Trata-se de necessidades que, por serem históricas, assumem especificidades no tempo e no espaço. Nessa concepção, o trabalho engendra um princípio formativo ou educativo". Lima, J.C.F., \& Neves, L.M.W., org. (2006). Fundamentos da educação escolar do Brasil contemporâneo [online]. Rio de Janeiro: Editora FIOCRUZ.
} 


\section{Metodologia}

A metodologia utilizada no presente trabalho foi a pesquisa bibliográfica. Nesse sentido, em um primeiro momento foi realizada a revisitação do processo de colonização do Brasil, particularmente, da escravização de negros africanos, visando à obtenção de elementos que pudessem contribuir para compreensão do contexto histórico de desigualdade no acesso à educação de pretos e pardos.

No segundo momento, foram levantados dados estatísticos junto ao IBGE concernentes à escolarização da população negra em comparação à população branca, corroborando a grande desigualdade existente, bem como a persistência dessa situação ao longo das décadas.

Analisou-se também como a política de cotas instituída pela Lei 12.711/12 vem contribuído para o ingresso desses sujeitos nas instituições federais. Para tanto, foram apresentados dados da Secretaria de Políticas de Promoção da Igualdade Racial da Presidência da República (SEPPIR) referente aos anos iniciais de implantação dessa política afirmativa, especificamente, anos de 2013 e 2014. A fim de analisar e demonstrar a evolução das vagas reservadas no âmbito dos Institutos Federais foram levantados dados oficiais junto a Plataforma Nilo Peçanha referente ao ano de 2019.

Após a constatação da efetividade da política de cotas, através dos dados oficiais apresentados, foi proposta uma reflexão, seguindo a mesma diretriz metodológica a partir de livros, artigos, teses e dissertações, sobre a missão institucional dos Institutos Federais de Educação, Ciência e Tecnologia de ofertarem uma educação emancipadora, articulando o trabalho como princípio educativo.

\section{A Escravização de Negros no Brasil e a Dificuldade de Acesso à Educação}

A reflexão sobre a escravidão no Brasil mostra-se necessária para compreensão de que as desigualdades educacionais em nossa sociedade perpassam pelo crivo racial e estão intimamente relacionadas ao processo de colonização aqui desenvolvido.

Nesse contexto, o surgimento de novas identidades sociais a partir de raças nasce na América com o propósito de conferir legitimidade às relações de dominação impostas pela ideia de conquista e justificar a distribuição racista do trabalho. Quijano $^{2}$ (2005) esclarece que a ideia de raça, no sentido que se conhece modernamente, não possui lastro histórico antes da América. Isso porque, inicialmente, os termos espanhol, português e, mais tarde, europeu indicavam apenas procedência geográfica.

Contudo, alerta o referido autor, que no processo de colonização das Américas foram redefinidos e associados a uma conotação racial, a fim de se contrapor as novas identidades sociais que surgiam: negros, índios e mestiços. Essa classificação social básica da população a partir da ideia de raças instituída na América se mostrou como uma maneira eficiente de conferir legitimidade às relações de dominação impostas pela colonização. Tanto é assim, que "as atividades braçais e manuais eram destinadas aos negros, pobres e desvalidos. As atividades intelectuais eram reservadas aos filhos dos latifundiários e dos burocratas da Colônia e do Império". (Ciavatta, 2019, p. 74).

Fonseca (1968) pondera que essa mentalidade, pela qual se atribui desonra aos trabalhos manuais, perpassa todo o processo histórico brasileiro, do período Colonial à República. Inclusive, a ausência de trabalho manual chegou a ser condição para o desempenho de funções públicas, contribuindo para acirrar a divisão entre ricos e pobres.

\footnotetext{
${ }^{2}$ As autoras optaram por uma abordagem decolonial, propondo uma nova compreensão do processo de colonização. "A descolonialidade não consiste em um novo universal que se apresenta como o verdadeiro, superando todos os previamente existentes; trata-se antes de outra opção". (Mignolo, 2017, p. 15). Contudo, não é objeto do presente artigo o aprofundamento da temática. Para maior detalhamento e compreensão ver Quijano (2005), Mignolo (2017), Dussel (2005).
} 
Essa dualidade do ensino marca desde o início a educação profissional no Brasil, inaugurada no governo de Nilo Peçanha por meio do Decreto-Lei 7.566, de 23 de setembro de 1909. Isso porque, embora formalmente abolida a escravidão em 1888 a mentalidade escravocrata na sociedade brasileira era "uma característica marcante do comportamento das massas que se acostumaram, após três séculos a ligar trabalho com escravidão" e não aceitavam uma educação que estivesse vinculada à formação para o trabalho. (Fonseca, 1961, p. 68).

Os séculos de escravização de negros no Brasil foram rompidos lentamente após pressões internas e internacionais. Contudo, "o fato de serem libertados por força de lei não garantia aos negros os mesmos direitos de fato e todas as oportunidades dadas aos brancos em nosso país, sobretudo, às camadas mais ricas da população”. (Munanga, 2016, p. 107).

Não houve por parte do aparelho estatal qualquer tutela em favor do recém-liberto; não lhe foi oportunizado o acesso a terra, condição essencial para sobrevivência num país predominantemente agrário como o Brasil daquela época, não lhe foi pago qualquer tipo de indenização pela expropriação da sua força de trabalho; enfim, nenhuma garantia de direitos ou assistência foi prevista pelo Estado brasileiro.

Para Florestan Fernandes (2008) citado por Rodrigues (2019),

A desagregação do regime escravocrata e senhorial se operou, no Brasil, sem que se cercasse a destituição dos antigos agentes de trabalho escravo de assistência e garantias que os protegessem na transição para o sistema de trabalho livre. Os senhores foram eximidos da responsabilidade pela manutenção e segurança dos libertos, sem que o Estado, a Igreja ou qualquer outra instituição assumisse encargos especiais, que tivessem por objeto prepará-los para o novo regime de organização da vida e do trabalho. Essas facetas da situação humana do antigo agente do trabalho escravo imprimiram à Abolição o caráter de uma espoliação extrema e cruel. (Fernandes apud Rodrigues, 2019, p. 147).

Libertos, os negros são vistos como ignorantes e desqualificados para a indústria nascente, que a qualquer momento poderiam se rebelar. Essas "classes perigosas" e seus filhos, as crianças e órfãos que perambulavam pelas ruas eram "desvalidos da sorte", devendo ser amparados e regenerados. (Ciavatta, 2019).

Assim é que, as recém-criadas Escolas de Aprendizes Artífices, sob a justificativa de amparar os "deserdados da sorte", "desvalidos" e formar cidadãos úteis à nação, ofertava ensino profissional, primário e gratuito às crianças com idade entre 10 e 13 anos (Brasil, 1909). A intenção era possibilitar aos filhos dos "desfavorecidos da fortuna" condições que lhe garantissem a sobrevivência, a fim de afastá-los da "ociosidade ignorante, escola do vício e do crime”. (Brasil, 1909).

É nítido o caráter assistencialista da educação profissional que surge no país, enraizada no estigma da servidão e desvalorização do trabalho manual, com fortes bases escravocratas. Lado outro, a consolidação de oligarquias patriarcais latifundiárias e empresariais e uma elite intelectual inspirada nos pensadores europeus, possibilitou o acesso a uma educação diferenciada e, notadamente, desigual a uma pequena parcela da população.

Em 1937, por meio da Lei 378, as escolas de aprendizes artífices são transformadas em Liceus destinados ao ensino profissional em todos os ramos e graus e passam a se vincular ao Ministério da Educação e Saúde Pública. Cinco anos mais tarde, em 1942, o Decreto n 4.127 transforma os Liceus em Escolas Industriais e Técnicas. Em 1959, referidas Escolas são elevadas à categoria de autarquias, adquirindo autonomia pedagógica e administrativa e recebem a denominação de Escolas Técnicas Federais.

Em 2008, ocorre a reorganização da rede de instituições federais de educação profissional e tecnológica por meio da Lei N ${ }^{\circ} 11.892$ e a criação dos Institutos Federais de Educação, Ciência e Tecnologia (IFET), propondo a oferta de educação profissional e tecnológica de qualidade, em todos os níveis e modalidades.

Assim é que, sem descurar dos processos de disputa que permeiam o acesso à educação, os IFETs nascem com objetivos bem delineados pela Lei 11.892 e se apresentam estrategicamente importantes para romper com a dualidade de ensino persistente na sociedade brasileira, propondo uma formação humana, ativa e emancipatória. É sob essa perspectiva que 
se pretende analisar a contribuição da formação proposta pelos IFETs, a partir do acesso à educação oportunizada pela política de cotas.

Não se pode olvidar da grande importância da política de cotas implementadas a partir da Lei 12.711/12 que possibilita o acesso ao ensino técnico de qualidade proposto pelo IFETs, comprometidos com uma formação cidadã pautada por valores como a ética, inclusão e responsabilidade social. Contudo, antes de se falar em uma educação emancipadora é necessário garantir o acesso ao sistema educacional, que embora seja previsto como garantia de todos os brasileiros na Constituição Federal de 1988 ainda não é uma realidade.

\subsection{As cotas raciais e os desafios do ensino técnico e profissional sob uma perspectiva emancipatória: conhecendo e analisando dados}

A educação apresenta-se como uma das mediações do mundo do trabalho e de suas contradições, reproduzindo as relações sociais dominantes. Os conhecimentos científicos, técnicos e tecnológicos são objeto de disputa em nossa sociedade e "o que lhes dá caráter destrutivo, expropriador e alienador ou de emancipação humana é o projeto societário ao qual se vinculam e dentro do qual se desenvolvem". (Frigotto, 2012, p. 245)

Mesmo na escola a serviço do sistema capital, que negligencia o desenvolvimento das potencialidades humanas através do caráter formativo do trabalho, os jovens têm a oportunidade de acessar diversos tipos de conhecimentos, estes presentes no exercício teórico-prático da educação profissional. A totalidade social do processo educativo que gera a alienação, prevista pelo sistema, gera também a resistência que pode conduzir à sua superação. (Ciavatta, 2019).

Embora a educação profissional no Brasil seja marcada historicamente pela dualidade, a Lei $\mathrm{N}^{\circ} 11.892$, de 29 de dezembro de 2008 que criou os Institutos Federais de Educação, Ciência e Tecnologia (IFET) e reorganizou a rede de instituições federais de educação profissional e tecnológica, propôs uma nova concepção de formação e qualificação profissional. Pautada pela oferta de cursos, prioritariamente, integrados, capacitação e aperfeiçoamento de trabalhadores, a referida lei objetiva fomentar a formação e qualificação de "cidadãos com vistas na atuação profissional nos diversos setores da economia". (Brasil, 2008).

Além de estimular e apoiar os processos educativos que levem à geração de trabalho e renda os IFETs devem “[...] a partir de uma formação técnica contribuir para a emancipação do sujeito, ou seja, ensinar o saber fazer e também ensiná-lo a ser sujeito ativo, pensante e participativo". (Santos, 2018, p. 743)

Esclarece Gramsci (1995, p. 118) que "a escola profissional não deve tornar-se uma incubadora de pequenos monstros aridamente instruídos num ofício, sem ideias gerais, sem cultura geral, sem alma, mas apenas com olhos infalíveis e uma mão firme". Para romper com essa formação adstrita ao mercado é importante que a relação entre trabalho e educação, notadamente pelo caráter teórico-prático da educação profissional, seja norteada por uma concepção formativa do trabalho.

Nesse sentido, tem-se que a educação tecnológica proposta pelos IFETs pretende a superação do modelo dual ainda persistente nos itinerários formativos, notadamente em relação à dissociação do trabalho técnico do trabalho intelectual, bem como a cisão que esse modelo perpetua, ofertando um tipo de educação para a elite e outra, de segunda categoria, para os trabalhadores e seus filhos.

Essa proposta, "[...] é uma tentativa de superar a visão elitista e dominadora da educação que manteve a educação profissional com o papel de treinar o trabalhador sem dar-lhe uma educação de qualidade, legando-o a uma tarefa marginal, distante do mundo da produção técnico-científica e cultural". (Zatti, 2012) 
Não há como pensar na construção de uma sociedade justa e democrática sem a perspectiva da superação do dualismo educacional vigente, atrelada a mecanismos e estratégias de inserção numa educação profissional e tecnológica que se proponha emancipadora, como a preconizada pelos IFETs.

Conforme salienta Pacheco (2007) é essencial para concretização dos objetivos da Rede Federal de Educação Profissional e Tecnológica a adoção de medidas para democratizar o acesso aos cursos oferecidos, sob pena de a expansão e a qualificação desse sistema serem apropriadas pelas minorias já tão privilegiadas.

Isso porque, conforme já apontado, o acesso à educação na sociedade brasileira passa pelo crivo da cor e há evidente abismo na escolaridade entre os cidadãos brancos e pretos, conforme demonstraram os dados PNAD Contínua realizada no ano de 2019. Conforme o boletim informativo da PNAD Contínua de 2019 na "análise por cor ou raça, chama-se atenção para a magnitude da diferença entre pessoas brancas e pretas ou pardas”.

Embora essa desigualdade no acesso à educação esteja arraigada em nossa sociedade o debate sobre alternativas para inserção de grupos desfavorecidos no sistema educacional formal de ensino público, como a política de cotas, é relativamente recente.

A primeira instituição de ensino federal a propor mecanismos de modificação do grave contexto de exclusão racial no espaço universitário brasileiro foi a Universidade de Brasília (UNB), que através do Plano de Metas para Integração Social, Étnica e Racial aprovado no Conselho de Ensino, Pesquisa e Extensão (Cepe), no dia 6 de junho de 2003 estabeleceu que $20 \%$ das vagas do vestibular seriam destinadas a candidatos negros, além de prever a disponibilização de vagas para indígenas de acordo com demanda específica. A medida entrou em vigência no ano seguinte, com a publicação do edital N. $2 / 2004-1 .^{\circ}$ vestibular 2005, publicado em 6 de setembro de 2004.

A partir desse pioneirismo da Universidade de Brasília houve uma ampliação da discussão sobre esse tipo de política afirmativa. A constitucionalidade das cotas por critério étnico-racial instituída pela UNB foi questionada através da propositura da Arguição de Descumprimento de Preceito Fundamental (ADPF) 186, no Supremo Tribunal Federal (STF) pelo partido político Democratas (DEM). Em 26/04/2012 foi reconhecida a constitucionalidade do sistema de cotas raciais pelo plenário do STF, julgando-se improcedente a ADPF 186.

O reconhecimento da constitucionalidade do sistema de reserva de vagas baseada em critério étnico-racial pelo STF, somada à necessidade de se apresentar respostas urgentes à desigualdade no acesso à educação para pretos e pardos viabilizaram a regulamentação do sistema de cotas através da Lei 12.711/2012. A Lei federal foi sancionada em 29 de agosto de 2012 e possui a seguinte ementa: "Dispõe sobre o ingresso nas universidades federais e nas instituições federais de ensino técnico de nível médio". (Brasil, 2012).

Basicamente, há três critérios de classificação dentro do sistema previsto na lei de cotas, a saber: o primeiro está ligado ao fato do aluno vir de escolas públicas, o segundo, relacionado à renda familiar per capita e, o terceiro, à autodeclaração de cor/etnia, conforme a proporção observada no último Censo Demográfico do IBGE em cada Unidade da Federação.

Em relação aos IFETs a regulamentação da reserva de vagas está prevista nos artigos $4^{\circ}$ e $5^{\circ}$ da Lei $12.711 / 2012$, a saber:

Art. $4^{\circ}$ As instituições federais de ensino técnico de nível médio reservarão, em cada concurso seletivo para ingresso em cada curso, por turno, no mínimo 50\% (cinquenta por cento) de suas vagas para estudantes que cursaram integralmente o ensino fundamental em escolas públicas. (BRASIL, 2012).

Art. $5^{\circ} \mathrm{Em}$ cada instituição federal de ensino técnico de nível médio, as vagas de que trata o art. $4^{\circ}$ desta Lei serão preenchidas, por curso e turno, por autodeclarados pretos, pardos e indígenas e por pessoas com deficiência, nos termos da legislação, em proporção ao total de vagas no mínimo igual à proporção respectiva de pretos, pardos, 
indígenas e pessoas com deficiência na população da unidade da Federação onde está instalada a instituição, segundo o último censo do IBGE. (Redação dada pela Lei n 13.409, de 2016). (BRASIL, 2012).

A Lei de cotas estabelece, portanto, que no mínimo, 50\% das vagas das instituições federais de ensino técnico de nível médio sejam reservadas para estudantes provenientes de escolas públicas. Além de abrangente, por mirar diferentes expressões das disparidades sociais, a Lei de Cotas pode ser considerada potencialmente importante como estratégia para reduzir a estratificação social no acesso à educação. (Senkevics, 2016).

A Lei de Cotas é regulamentada pelo Decreto Federal № 7.824, de 11 de outubro de 2012, que também instituiu o Comitê de Acompanhamento e Avaliação das Reservas de Vagas nas Instituições Federais de Educação Superior e de Ensino Técnico de Nível Médio, composto por representantes do Ministério da Educação (MEC), da Secretaria de Políticas de Promoção da Igualdade Racial da Presidência da República (SEPPIR) e da Fundação Nacional do Índio (FUNAI).

Apesar de recente, com menos de uma década de implantação em âmbito nacional, a política de cotas raciais já aponta para algumas mudanças importantes na sociedade brasileira. Segundo dados de novembro de 2014, da Secretaria de Ensino Superior do Ministério da Educação (SesuMEC) apresentados pela SEPPIR, as vagas disponibilizadas para cotistas no referido período sofreram significativo aumento, conforme tabela abaixo.

Tabela 1 - Evolução do número de vagas destinadas a cotistas nos dois primeiros anos após a sanção da Lei 12.711/12.

\begin{tabular}{lllll}
\hline Ano & Universidades Federais & & Institutos Federais \\
& Total & Cotas & Total & Cotas \\
2013 & 221.650 & 70.849 & 44.507 & 20.448 \\
2014 & 243.383 & 98.121 & 52.414 & 24.222 \\
Total & 465.033 & 168.970 & 96.921 & 44.670 \\
\hline
\end{tabular}

Fonte: Secretaria de Ensino Superior (SESU/MEC), (2014).

Infere-se da Tabela 1 que entre 2013 e 2014 houve acréscimo de 21.733 novas vagas ofertadas, equivalente a aproximadamente $10 \%$ das vagas totais disponibilizadas pelas Universidades Federais. Quando se analisa especificamente as vagas destinadas a cotistas observa-se no mesmo período um acréscimo de 27.272 , que equivale aproximadamente a $38 \%$ de novas vagas. Já nos Institutos Federais, no mesmo período, houve acréscimo de 3.774 novas vagas para cotistas.

Ainda segundo a SEPPIR, entre 2013 e 2015 a política de cotas garantiu o acesso a aproximadamente 150 mil estudantes negros em instituições de ensino superior em todo o país. Em comparação com o ano de 1997, o percentual de jovens negros, entre 18 e 24 anos, que cursavam ou haviam concluído o ensino superior era de 1,8\% e o de pardos, 2,2\%. Em 2013, esses percentuais já haviam subido para 8,8\% e 11\%, respectivamente. (SEPPIR, 2016).

Denota-se que a implementação da Lei 12.711/2012 na rede federal de ensino significou, já nos seus primeiros anos de implantação, o aumento expressivo da reserva de vagas, demonstrando o potencial de inserção para negros e pardos através dessa política afirmativa, especialmente nos Institutos Federais.

Em parte, isso pode ser atribuído ao fato de que, ao ser fixado um percentual mínimo de vagas pela Lei para cada critério estabelecido, impediu-se a utilização de reserva de vagas baseada no quantitativo de inscritos no vestibular pertencentes a determinado grupo de cotas, o que era utilizado anteriormente em algumas universidades, acarretando muitas vezes, a reserva de vagas em número baixo e incerto. (Feres Júnior et al., 2013).

Segundo Eurístenes (2016), antes da Lei 12.711/12 aproximadamente 36\% das Universidades Federais e Institutos Federais não possuíam qualquer política voltada para inclusão de pretos e pardos. A obrigatoriedade da adoção de política de 
cotas para todas as universidades e institutos federais fez com que as instituições que ainda resistiam às ações afirmativas fossem compelidas a adotá-las, a fim de dar cumprimento à nova lei.

Não obstante a importância de se fazer o acompanhamento da política de cotas, conforme prevê o art. $6^{\circ}$, da Lei 12.711/12, constata-se que os dados existentes, bem como as pesquisas realizadas ainda são incipientes. Apenas no ano de 2017 foi criada a Plataforma Nilo Peçanha (PNP) que tem como objetivo a coleta, validação e disseminação das estatísticas oficiais da Rede Federal de Educação Tecnológica. Não obstante a disponibilização de diversos dados na plataforma, somente no ano base de 2019 foi incluído espaço para disponibilização de informações sobre o cumprimento da lei de cotas.

Os indicadores da Plataforma Nilo Peçanha são monitorados pela Secretaria de Educação Profissional e Tecnológica do Ministério da Educação (SETEC/MEC). Os dados mais recentes foram publicados na referida plataforma em junho de 2020 e comprovam que mais de 235.000 (duzentos e trinta e cinco mil) vagas foram ofertadas em todos os campi da rede federal de educação profissional e tecnológica no ano de 2019, conforme demonstra a tabela abaixo.

Tabela 2 - Número de vagas ofertadas aos cotistas nos processos seletivos dos Institutos Federais no ano de 2019 em cumprimento a Lei 12.711/12.

\begin{tabular}{|c|c|c|c|c|c|c|c|c|c|c|}
\hline Curso & $\begin{array}{l}\text { Vagas } \\
\text { Edital }\end{array}$ & $\begin{array}{l}\text { Vagas } \\
\mathrm{AC}^{1}\end{array}$ & $\begin{array}{l}\text { Vagas } \\
\text { RI }\end{array}$ & $\begin{array}{l}\text { Vagas } \\
\text { RI-PPI }\end{array}$ & $\begin{array}{l}\text { Vagas } \\
\text { RI- } \\
\text { PcD }\end{array}$ & $\begin{array}{l}\text { Vagas } \\
\text { RI- } \\
\text { PPI- } \\
\text { PcD }\end{array}$ & $\begin{array}{l}\text { Vagas } \\
\text { RS }\end{array}$ & $\begin{array}{l}\text { Vagas } \\
\text { RS } \\
\text { PPI }\end{array}$ & $\begin{array}{l}\text { Vagas } \\
\text { RS - } \\
\text { PcD }\end{array}$ & $\begin{array}{l}\text { Vagas } \\
\text { RS- } \\
\text { PPI- } \\
\text { PcD }\end{array}$ \\
\hline Técnico & 175.321 & 88.801 & 14.131 & 20.385 & 3.704 & 4.884 & 16.740 & 17.823 & 4.242 & 4.611 \\
\hline Graduação & 77.829 & 39.317 & 6.889 & 9.096 & 1.576 & 1.902 & 6.757 & 8.710 & 1.779 & 1.803 \\
\hline Total & 235.150 & 128.118 & 21.020 & 29.481 & 5.280 & 6.786 & 23.497 & 23.533 & 6.021 & 6.414 \\
\hline
\end{tabular}

${ }^{1}$ Legenda: AC: Ampla concorrência; RI: Renda Inferior (1,5 salário mínimo); PPI: Preto/Pardo/Indígena; RS: Renda Superior (1,5 salário mínimo); PcD: (Pessoa com deficiência). Fonte: Plataforma Nilo Peçanha (2020).

Evidencia-se expressivo aumento na oferta de vagas reservadas na rede federal de educação, vez que entre 2013 e 2014 foram ofertadas 44.670 vagas para cotista, conforme demonstrado na tabela 1, enquanto que no ano base 2019, subtraindo-se as vagas da ampla concorrência da totalidade de vagas ofertadas para os cursos técnicos e de graduação se obtêm um resultado de 107.032 vagas reservadas para cotistas.

Verifica-se que, nos últimos cinco anos, o aumento do número de vagas para cotas, mais que dobrou nas redes federais de ensino tecnológico, demonstrando a importância dessa política afirmativa para superação da exclusão social.

Contudo, entende-se que para a superação da desigualdade devam ser implementadas medidas par além do ingresso, ações ligadas à cidadania através de uma educação emancipadora, atrelada a construção de uma nova sociedade fundada na igualdade política, econômica e social: vinculando a escola ao mundo do trabalho numa perspectiva radicalmente democrática e de justiça social. (Pacheco, 2007).

Assim é que, a educação tecnológica ofertada pelos Institutos Federais deve se apresentar como um contraponto ao conhecimento fragmentário frequentemente verificado nos cursos técnicos, a fim de que a unidade entre teoria e prática possibilite ao trabalhador manifestação plena de si mesmo, independente das atividades e ofícios que exerce. (Manacorda, 2010).

Essa possibilidade de desenvolvimento integral do individuo a partir do trabalho como princípio educativo decorre do fato de que como seres da natureza todos os seres humanos têm necessidades semelhantes, quais sejam, de se alimentarem, 
protegem-se, enfim, de proverem condições para subsistência, sendo que o trabalho é meio comum a todos de atingirem esses fins. Essa ideia de que os seres humanos criam e recriam sua própria existência a partir de respostas as suas necessidades vitais básicas, transcendendo sua natureza orgânica e constituindo-se como ser social, pressupõe uma formação humana, ativa e apta à compreensão e superação da realidade. (Frigotto, 2012).

Por isso, o trabalho como princípio educativo é intrínseco ao processo de constituição do ser humano como ser social. Assim, não assume de per si uma característica de prática pedagógica a ser ensinada no ambiente escolar, porque é algo natural e orgânico que não se distancia da própria constituição do ser, viabilizando o desenvolvimento do ser humano na sua totalidade e complexidade, nas suas diversas interfaces e necessidades.

Nesse sentido, não há como dissociar o trabalho como princípio educativo de uma educação emancipadora, já que o aluno é conduzido ao desenvolvimento de capacidades que articulem o pensamento crítico, posicionamento e interferência frente à realidade, traduzindo-se numa capacidade de pensar e fazer sua própria história.

É exatamente por isso, que o objetivo de inserir pessoas por meio do ensino e torná-las agentes transformadores da realidade em que vivem somente pode ser alcançado numa perspectiva emancipatória, que embora seja bastante desafiadora é possível de ser implementada.

Por certo, os IFETs não podem se afastar dos objetivos estratégicos para os quais foram criados, devendo apoiar e estimular processos educativos que possibilitem a emancipação econômica, social e política do cidadão. Essa proposta não é de uma educação qualquer, mas de uma educação vinculada a um Projeto Democrático comprometido com a emancipação dos sujeitos excluídos da nossa sociedade, assimilando e superando os princípios da sociedade organizada para assumir um papel amplo na superação da exclusão social. (Pacheco, 2007.)

\section{Considerações Finais}

O longo processo de escravização de negros na sociedade brasileira arraigou ideologias preconceituosas e discriminatórias na vida pública e privada, além de deixar marcas sociais, políticas e culturais profundas. O aviltamento dos trabalhadores com a desqualificação do trabalho manual também tem fortes raízes nesse processo de escravização. Isso implicou tanto na estigmatização do trabalho manual quanto na dualidade do ensino ofertado, vez que aos filhos das elites era ofertado os maiores graus de ensino e para maioria da população apenas o ensino primário e profissional, como acontecia nas escolas de aprendizes artífices.

Ainda é um grande desafio assegurar o acesso universal à educação, vez que, não obstante se tratar de direito social constitucionalmente assegurado, tem sido relegado a grande parte da população, especialmente aos pretos e pardos, conforme demonstram os dados da PNAD Contínua 2019, realizada pelo IBGE.

Essa conjuntura demonstra a necessidade de políticas públicas que viabilizem o acesso à educação de forma igualitária. Nesse contexto, insere-se o debate sobre a política de cotas implementadas em âmbito nacional a partir da promulgação da Lei Federal 12.711/12. Essa lei tem se mostrado um importante mecanismo para ampliação do acesso à educação, especialmente para pretos e pardos, historicamente renegados. Contudo, essa inclusão não pode estar apartada da ideia de emancipação, que se constitui como um dos pilares para construção de uma sociedade mais justa e igualitária.

Assim é que, os Institutos Federais por serem instituições públicas presentes em todo o território nacional e que também estão submetidas ao cumprimento da reserva de vagas para pretos e pardos contribuem notoriamente para ampliação do acesso a uma educação de qualidade, mas para além da formação técnica e profissional para qual são vocacionados articulam trabalho e educação numa perspectiva ontológica, consolidando a missão institucional desses estabelecimentos na 
entrega de uma formação emancipadora, comprometida com a transformação da sociedade, dos sujeitos e da superação da exclusão social.

Demonstrou-se que a efetividade da Lei de Cotas deve ser analisada sob uma perspectiva que ultrapasse o mero ingresso. Sugere-se, por isso, que estudos futuros se debrucem sobre as instituições federais, especialmente os Institutos, para verificar se existem políticas internas que contribuam para a permanência, êxito e visibilidade dos cotistas, a fim de subsidiar informações que possam contribuir, nesse esforço coletito, para que de fato essas instituições se tornem cada vez mais inclusivas e democráticas.

\section{Referências}

Brasil. (2016). Ministério da Educação. Histórico. http://redefederal.mec.gov.br/historico.

Brasil.(1988). Constituição da República Federativa do Brasil, $1988 . \quad$ Brasília, DF: Senado $\quad$ Federal. http://legis.senado.leg.br/legislacao/ListaTextoIntegral.action?id=249346\&norma=102408.

Brasil. (2008). Lei $\mathrm{n}^{\circ}$ 11.892, de 29 de dezembro de 2008. Institui a Rede Federal de Educação Profissional, Científica e Tecnológica, cria os Institutos Federais de Educação, Ciência e Tecnologia, e dá outras providências. http://www.planalto.gov.br/ccivil_03/_Ato2007-2010/2008/Lei/L11892.htm

Brasil. (2012). Lei $\mathrm{n}^{\circ}$ 12.711, de 29 de agosto de 2012. Dispõe sobre o ingresso nas universidades federais e nas instituições federais de ensino técnico de nível médio e dá outras providências. http://www.planalto.gov.br/ccivil_03/_ato2011-2014/2012/lei/112711.htm

Brasil. (1909). Decreto Lei 7.566 de 23 de setembro de 1909. Cria nas capitais dos Estados da Escolas de Aprendizes Artífices, para o ensino profissional primário e gratuito. http://portal.mec.gov.br/setec/arquivos/pdf3/decreto_7566_1909.pdf.

Ciavatta, M. et. al. (2019) A historiografia em trabalho educação: como se escreve a história da educação profissional. Uberlândia: Navegando publicações.

Fonseca, C. S. (1986). História do Ensino Industrial no Brasil. v.5. Rio de Janeiro: SENAI/DN

Frigotto, G.; \& Ciavatta, M. et. al. (2019). A historiografia em trabalho educação: como se escreve a história da educação profissional. Uberlândia: Navegando publicações.

Frigotto, G.; Ciavatta, M., \& Ramos, M. (2012). Ensino Médio integrado: concepções e contradições. São Paulo: Cortez.

Gramsci, Antonio. (1995). Os Intelectuais e a Organização da Cultura. Rio de Janeiro: Civilização Brasileira..

Gomes. Laurentino. (2019). Escravidão - do primeiro leilão de cativos em Portugal até a morte de Zumbi dos Palmares. Vol. I. Rio de Janeiro: Globo Livros.

Instituto Brasileiro de Geografia e Estatística. (2020). Pesquisa Nacional por Amostra de Domicílios Contínua, 2019. https://biblioteca.ibge.gov.br/visualizacao/livros/liv101736_informativo.pdf.

Manacorda, Mário Alighiero. (2010). Marx e a pedagogia Moderna. Tradução: Newton Ramos de Oliveira. Campinas, SP: Editora Alínea.

Mattos, W. R. (2009). Mattos, W. R. de. (2009). Aspectos Históricos da Exclusão Racial: Ou como Nós, Historiadores Negros, Podemos Contribuir com o Debate Contemporâneo sobre as Ações Afirmativas. In: Silvério, V. R. e Moehlecke, S. (orgs.). Ações Afirmativas nas Políticas Educacionais. O Contexto Pós-Durban. São Carlos: EdUFSCar.

Munanga, K.; \& Gomes, N. (2016). O negro no Brasil de hoje. São Paulo: Global.

Munanga, K. (2015). Por que ensinar História da África e do Negro no Brasil de hoje? In: Revista do Instituto de Estudos Brasileiros, Brasil.

Nedilson, Jorge, (org.). (2018). História da África e relações com o Brasil: 1.ed. Brasília : FUNAG.

Pacheco, E. (2007). Nova Perspectiva para a Rede Federal de Educação Profissional e Tecnológica. Brasília/DF, 2007. http://portal.mec.gov.br

Quijano, A. (2005). Colonialidade do poder, eurocentrismo e América Latina. In: LANDER, Edgardo (org). A colonialidade do saber: eurocentrismo e ciências sociais. Perspectivas latinoamericanas. Buenos Aires, Colección Sur.

Rodrigues, E. B. (2010). Igualdade e ações afirmativas nos Estados Unidos e no Brasil. In: Novelino, M. (Org.). Leituras complementares de direito constitucional: direitos humanos e direitos fundamentais. 4. ed. rev. atual. aum. Salvador: JusPodivum..

Senkevics, A. S.; \& Mello, U. M. (2018). Panorama de dados e indicadores para monitoramento da Lei de Cotas. Caderno de Estudos em Políticas Educacionais. Brasília, DF: INEP.

Silva. A. et al. (2009). Entre o racismo e a desigualdade: da constituição à promoção de uma política de igualdade racial. In: Jaccoud, L. (Org.). A construção de uma política de promoção da igualdade racial: uma análise dos últimos 20 anos. Brasília.

Silverio, V. R.; \& Moehlecke, S. (Orgs.).(2009) Ações Afirmativas nas políticas educacionais: o contexto pós-Durban. São Carlos: EDUFSCar.

STF. ADPF 186. (2012). http://www.stf.jus.br/arquivo/cms/noticianoticiastfarquivo/anexo/adpf186.pdf.

Zatti, Vicente. (2012). Educação técnico-científica emancipatória nos IFETs: um olhar através de Habermas e Freire. Tese (Doutorado em Educação). Universidade Federal do Rio Grande do Sul, Faculdade de Educação, Porto Alegre. 